\title{
Associated Microorganisms in Marine Cnidarians, Their Ecological Function in Symbiotic Relationship
}

\author{
Zhi-Gang Qiu ${ }^{1}$, Yihua Lyu ${ }^{2}$, Jin Zhou, ${ }^{3, *}$ \\ ${ }^{1}$ Shenzhen Zhongxing Environmental Instruments Limited Company, Shenzhen, China \\ ${ }^{2}$ South China Sea Environment Monitoring Center, State Oceanic Administration, Guangzhou, China \\ ${ }^{3}$ The Graduate School at Shenzhen, Tsinghua University, Shenzhen, China
}

\section{Email address:}

qiu.zhigang@zeei.com.cn (Zhi-Gang Qiu),840430459@qq.com (Yihua Lyu), aqudiszhoujin@163.com (Jin Zhou)

\section{To cite this article:}

Zhi-Gang Qiu, Yihua Lyu, Jin Zhou. Associated Microorganisms in Marine Cnidarians, Their Ecological Function in Symbiotic Relationship. Earth Sciences. Vol. 4, No. 5, 2015, pp. 180-187. doi: 10.11648/j.earth.20150405.13

\begin{abstract}
Cnidarians (e.g. coral reefs) are among some of the most diverse and highly productive coastal ecosystems in tropical and subtropical regions. Microbes play pivotal roles in maintaining this productivity and are directly responsible for the well-being of a coral-based ecosystem. Microbes have important ecological functions in this ecosystem. With the acceleration of globalization and the deepening of molecular researches, the role and functions of microbes in the corals are increasingly highlighted. In this paper, the recent achievements were analyzed to summarize the research status of coral-associated microbial ecology, including the formation of coral-microbe symbionts, characteristics of symbiotic microbes (specificity, plasticity and co-evolution), as well as the microbial signaling strategies. The aims are help to define the crucial ecological interactions between coral reefs and microbes, and provide a better understanding of microbial ecosystem function and coral remediation.
\end{abstract}

Keywords: Cnidarians, Microbes, Ecological Role, Global Change, Review

\section{Introduction}

As a cnidarians, coral reef is a marine ecosystem with extremely high productivity, high biodiversity and important economic value, and therefore it is known as "tropical rainforest in the ocean"(Fig. 1). The data show that the average annual economic value of global coral reefs reached 375 billion dollars [1]. The creatures in coral reef ecosystems with the largest quantity are microbe, the quantity of which is approximately 20 times that of free water [2]. As producer and decomposer, the microbes extensively participate in substance cycle, energy flow and various oxidation-reduction activities, and regulate the balance and stability of coral reef ecosystems, which is the most basic and active link in the whole coral-associated ecosystem [3]. Whittaker [4] deemed that the primary productivity of coral reef in unit area is close to that in rainforest and can reach $5-10 \mathrm{~g} \cdot \mathrm{cm}^{-2} \cdot \mathrm{d}^{-1}$. The contribution rate of benthic algae is about $1 / 3$, and that of microbes and other creatures is $2 / 3$. The research on the species diversity and functional diversity of coral-associated microbes is important for the understanding of energy supply and physical health of corals, as well as the complexity, diversity and vulnerability of coral reef ecosystem.
With the improvement of microbial culture method, development of molecular techniques and maturation of high-throughput analysis method, the research range of microbes has been broadened. Therefore, great progress has been made in the interaction between the corals and microbes, and many ecological processes and mechanism of microbes in the coral ecosystem have been revealed [5]. The advance of microbial ecology in coral environment was summarized in this review by highlighting the genesis of "coral-microbe" symbiont, functions of microbes inhabiting the reefs, influence of microbes on the ecological health of coral reefs, and the response of microbes to the global climate change. The purpose is to understand the dynamic process of coral ecosystem from the viewpoint of microbial ecology, and to speculate the research focus in the future, so as to provide a more comprehensive knowledge for the protection of biodiversity and maintenance of functional diversity in the coral reef ecosystem.

\section{Formation of Host-Microbe Symbionts}

Determining the formation process and mechanism of coral-microbe community is the premise for understanding 
the functions of coral holobiont, including the microbial colonization pattern, the driving forces for the formation of holobiont and the transmission routes of microbes.
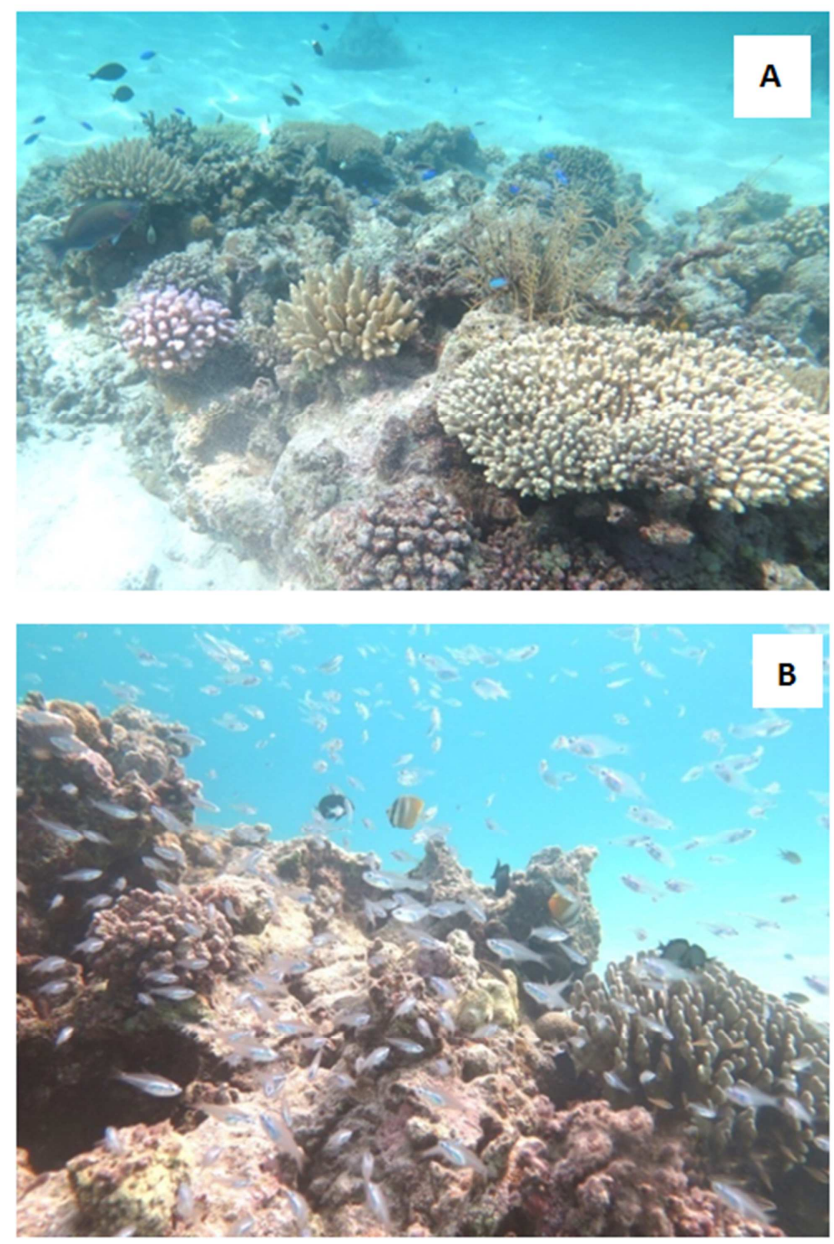

Figure 1. The coral reefs demonstration sites in the South China Sea (A), and we can see relatively high biodiversity in this ecosystem (B).

In previous researches, it was believed that the original colonization is caused by random collision and adhesion of surrounding microbes. The molecular research about the colonization of epiphytic bacteria of corals indicated that the bacterial community in the mucus of corals is the result of the selection by the coral symbiont itself, rather than the occasional adhesion of bacteria in sea water [6]. The research on the Cnidarian hydra indicated that the composition of bacterial community attached on the coral surface is directly determined by the metabolism of the host and the secretion of microbial biofilm in mucous layer, which attract the passing microbes and regulate their colonization behavior in the coral mucous layer [7].

After the bacterial colonization, the diversity and structure are gradually established, and the symbionts advance towards maturity. It was indicated in previous study that the driving forces for the formation of symbionts include two major aspects: 1) the individual development at early stage, 2) the metamorphosis from larvae to adults. By comparing the T-RFLP fingerprints of bacteria at different reproductive stages of corals (oocyte, egg and planula), Apprill et al [8] demonstrated the genesis of microbial biomes in Pocillopora meandrina, and found that the DNA of the bacteria at different stages was basically consistent, but only with a little difference. However, after the complete development of planulae, the difference of bacterial composition was enlarged due to the endocytosis of corals. This difference was driven by the behavioral changes of planulae (prone to benthic attachment). The individual transformation from larvae to adults also provides some evidences for the formation of symbionts, including the stochastic sequences in clone library, DGGE cluster and diversity analysis. The cluster analysis indicated that the microbial populations in the adults of Acropora tenuis and Acropora millepora had higher clustering degree, while those in the larvae showed lower clustering degree [9]. Compared with the adults, the larvae had higher diversity of bacteria and diversified complementarities. By comparing the composition of diversity, it was found that some similar bacterial communities appeared in both larvae and adults. However, some symbiotic bacteria adhering on the adults could not be found in the larvae, which indicate the structural succession of symbiotic bacteria in the growing process of corals. The symbiotic bacteria of the adults gradually substituted the composite microbial system of the larvae, and developed towards the diversified and stabilized direction. This structural succession was driven by the transition of morphology [9]. In future research, the succession of microbes in the development process of the individuals of coral should be further studied, so as to determine the formation time and method of species specificity and the symbiotic behavior in various coral species.

There are two major opinions about the transmission approaches of microbes in the colonization process, that is, vertical approach and horizontal approach. The horizontal approach is more widely accepted. By studying the Porites astreoides in Caribbean Sea, Sharp et al [10] found that some bacteria in the host were transmitted to the offspring, and they first proposed the theory of vertical transmission. However, this theory cannot be extended to other corals, such as Scleractinia sp. Moreover, this form of inheritance was not found in another eight varieties being studied [8]. For example, the composition of epiphytic bacteria in the parental generation and filial generation of Pocillopora meandrina at different reproductive stages was analyzed, and the result showed significant difference of microbial communities. The similarity of microbial communities in different development stages reached $83 \%$, which means that the symbiotic bacteria of Pocillopora meandrina were transmitted by horizontal approach [8]. In addition, Wegley et al [11] used the planulae of Porites sp. to study the colonization and diversity of bacteria. The result confirmed that the bacterial colonization in Porites sp. occurred in the planula or post-adhesion stage. Several phylotypes found in the two stages were also detected in the adults, which mean that the corals acquired certain species of bacterium by horizontal approach. Sharp et al [10] and Apprill et al [8] 
detected similar phylogenetic branches in the 16s rRNA gene clone library of the larva specimens of Pocillopora meandrina, which suggested that the different coral varieties possessed some common species of bacteria. This also verifies the existence of horizontal transmission. Among these common bacteria, the most common was Roseobacterial sp., followed by Ruegeria sp. and Alpha proteobacteria sp. (such as Silicibacter) [12-14]. Although the definite role of these bacteria in the corals is still unknown, their extensive existence at the early stage and reproductive stage indicates its necessity to the individual development of corals [8].

\section{Specificity, Plasticity, and Co-evolution of Symbiotic Microbes}

Along with the increasingly aggravated pressure on coral reefs from environmental changes, a critical question needs to be answered: can the corals and symbiotic bacteria change the function of symbionts by a certain particular mechanism (recombination or substitution) to respond to the challenge from environmental changes? Therefore, the knowledge about the specificity and plasticity of epiphytic bacteria is vital to understand the functional evolution and environmental adaptability of the symbionts. On the premise of the existence of specificity and plasticity, the co-evolution between the coral host and the symbiotic bacteria will be generated on the long-term temporal scale, which is favorable for both of them. Currently, the researches on the specificity and plasticity mainly focus on the temporal and spatial scales. The former concerns the symbiotic relationship at different development periods of corals and at different seasons, and the latter focuses on the symbiotic characteristics of nonspecific or heterogenic coral in different regions [15].

The specificity between the coral host and the symbiotic bacteria under the category of genus was proved by the sequence-based assessment for microbial community. For example, some bacteria only exist in specific reef-building corals. Rohwer et al [2] described the bacterial communities of three coral varieties of the Caribbean Sea. About 6000 genotypes were found in the sequence library of the 14 coral samples, and the symbiosis of these bacteria and the corals was stable on temporal scale. Some similar results were also obtained from the studies on various coral varieties and bacterial communities in different geographic regions [5]. Lately, Sogin et al [15] analyzed the microbial diversity in the same coral species in different regions by using micro-diverse clusters, and found that the similarity of microbial molecular sequences exceeded $90 \%$. This means that the microbial communities of corals in two regions were occupied by some basically identical systematic unit. In the differential molecular sequences, the species-distribution curve of the samples in two regions had a longer trailing, which indicates the existence of rare species at a certain quantity. Actually, in Fiore et al [16] research, them using
454 pyrosequencing tool demonstrated that the symbiotic prokaryotic communities of X.muta were significantly different than the surrounding bacterioplankton communities while an analysis of similarity (ANOSIM) of the sponge prokaryotic symbionts from three geographically distant sites showed that both symbiont and bacterioplankton populations were significantly different between locations.

The existence of specificity between the coral host and symbiotic bacteria is the premise for maintaining the stability of symbionts. Due to the longer life cycle of corals, the composition and proportion of symbionts will change with the environment. The symbiotic relationship between the two changes from endo-symbiosis to co-evolution, showing a certain plasticity, which is achieved by the switch or shuffle of the symbiotic bacteria. Switch refers to that the coral host acquires the new type of bacteria from external environment, and shuffle refers to that the host transforms the intrinsic bacterial types and the relative quantity. More and more experiments confirmed the feature of plasticity. The research by Long and Azam [17] indicated the consistency of specific bacterial species in corals in terms of geographical location. When the environment changed, the bacterial communities showed inconsistency on the different spatial scales in the same habitat [from several meters to several kilometers]. This type of physiological plasticity facilitates the positive response of corals to the environmental stress. Rohwer et al [5] pointed out the difference in the composition of epiphytic bacteria of three congeneric corals in Panama and the Bermuda Islands. It is a type of shuffle based on latitudinal adaptability, showing its adaptation to water temperature. This shuffle did not result in great fluctuation on the level of lineage, but only the sub-lineage level showed a certain fluctuation. This not only maintained the stability of the symbionts, but also acquired the buffer capacity of responding to the environmental variation. There is still controversy on whether the plasticity belongs to active behavior or passive behavior. Some scholars believed that it is active and pointed out that the crucial question of microbial ecology is whether the microbes occupy the niche of complex community, or there is functional redundancy in the community $[18,19]$. The occupation of niche by microbes is an internally-driven behavior. The change with the environment of the host is also adaptability, and the switch belongs to neutral selection. Therefore, they contended that the plasticity is an active behavior. However, others supported the opinion of passive behavior. The microbial communities showed heterogeneity between the habitats with the same productivity [20]. The corals in different geographical locations had different bacterial genes, and the similar corals were colonized by the bacteria with similar genotypes [21], which indicate that the plasticity is a passive effect. Moreover, life activity is basically energy-saving. When the living condition of a matured symbiotic system changes, the organism has to consume a certain energy to create a new suitable condition. This response belongs to passive action, and indirectly verifies the passivity of the plasticity [22]. Jensen et al [23] have also proved it by 
analysis deep-sea coral reef at mid-Norwegian coast using a combination of cultivation and small subunit (SSU) rRNA gene and transcript sequencing However, whether the plasticity is active or passive, it is a method for maintaining the optimal condition of coral symbionts, which aims at the maximization of the health benefits of coral symbionts [2].

Co-evolution refers to the process of mutual adaptation between two species under the stress of natural selection. It is one of the main driving forces for the existence and evolution of species. The previous study indicated that the relationship between the coral host and the symbiotic bacteria showed phylogenetic consistency on the category of genus and the tendency of co-evolution. Moreover, the mutated TSI rDNA (transcriptionally silent information rDNA) molecular marker was employed to study the relationship between corals and algae, another pair of symbiont, and the existence of co-evolution between the host and the symbiotic algae in the reef-building scleratinian coral and Octocorallia was confirmed [24]. It is the beginning of the research about the co-evolution of the symbionts. However, the experiments about the co-evolution of microbes are not yet started. The high diversity of microbes brings a large amount of work and huge challenge for the research on the co-evolution between the corals and microbes. Fortunately, the maturation of high throughput method and new molecular marker technique may aid the revealing of the formation of co-evolution and the corresponding mechanism.

\section{Functions of Symbiotic Bacteria}

\subsection{Biogeochemical Cycle}

It was once believed that the nutrients of corals in oligotrophic condition came from the photosynthesis of epiphytic algae. However, the latest studies by culture technique or non-culture technique indicate that the effect of microbes on the biogeochemical process of coral reefs might have more contribution. For example, nitrogen fixation by microbes was proved using acetylene reduction assay [25]; the nitrogen-fixing genes were found in several coral varieties from different regions [26, 27]; several enzymes related to nitrogen fixation were found in the genome of symbiotic bacteria of Porites sp, and its nitrogen-fixing mechanism was basically consistent with that of blue algae [28]. There are more populations with nitrogen fixation function in the symbiotic microbes of corals. The research on the nifH genetic diversity of two species of Montipora of Hawaii indicated that the nitrogen-fixing bacteria in the corals not only included cyanobacteria, but also other varieties, such as $\alpha, \beta, \gamma$ and $\Omega$-Proteobacteria [29]. It has been proved recently that the epiphytic microbes of corals may participate in other nitrogen cycle processes, including nitrification, ammonification and denitrification [11]. Meanwhile, the microbes attached to the corals also participate in the carbon and sulfur cycles [30]. The genes regulating the carbon fixation, carbon decomposition and sulfur assimilation have been detected in the epiphytic algae of the corals [31]. The existence of these functional genes and gene fragments cannot guarantee the performance of biological functions, but it indicates that the substance processing capacity of the bacteria has a certain ecological amplitude. In Fiore et al [32] work, they found that sponge metabolism and its prokaryotic symbionts may have a significant impact on the nitrogen biogeochemistry on Caribbean coral reefs by releasing large amounts of DIN. In future, more in situ data or expression-based researches are required to clarify the effect of microbes on the driving of substance cycle in the coral reefs [33].

Besides the metabolism and cycle of substances, the bacteria also regulate the ecological behaviors of corals. Relevant genomic data indicate that there are several genes decomposing aromatic compounds in the Porites astreoides, and these genes can help the coral host to eliminate particular pollutants to achieve self-cleaning [11]. Wild et al [34] indicated that the epiphytic bacteria of corals participate in the processing of mucous particles and decompose the organic compounds around the reefs. Literature indicated that crustose coralline algae (CCA) can facilitate the attachment of the larvae of two endangered Sinularia species (Sinularia cervicornis and A. palmate) in Florida Islands and the Caribbean Sea. The mechanism is that the epiphytic bacteria on the surface of CCA induce the proliferation of $\beta$-Proteobacteria and the formation of biofilms, and then the existence of biofilms induces the attachment and metamorphism of coral larvae [35-36]. The latest study indicated that the exposure to the isolates of Pseudoalteromonas cultured in Negoniolithon fosliei increased the metamorphic rate of Acropora millepora [37]. Other Pseudoalteromonas and Thalassomonas isolates can also induce the attachment and metamorphism of the larvae of Pocillopora damicornis with a certain selectivity. Moreover, the inductivity of the bacteria from different origins (algal or coral surface) is not completely consistent. On the whole, the attachment and metamorphism of the coral larvae are regulated by the bacterial behaviors in the benthic environment [38].

\subsection{Pathogen Resistance}

Besides the biogeochemical cycle, the symbiotic bacteria of corals play a positive role in disease resistance, maintenance of host health and ecological stability by competing for more nutrients and space, and thus generating antibiotics [39-40]. Recent studies mostly focus on the original bacteria in the mucous layer on the coral surface as these bacteria regulate the bacterial colonization in the mucus, and finally affect the resistance to diseases. It was indicated that some bacteria isolated from the coral mucus can secrete antibiotics, so they can withstand the attack of indicator bacteria (i.e. Escherichia coli and Staphylococcus aureus) and invasive pathogens (i.e. Vibrio sp.) [41,42]. A large amount of genes related to anti-bacterial compounds have been detected from the metagenome of multiple coralsc [43]. Moreover, the coral mucus selectively resists the symbiotic bacteria. The mechanism is the allelopathic effects between 
bacterial strains, which is realized by quantity competition [44]. The coral mucus contains high-concentration of organic matter and inorganic matter, which will result in the rapid proliferation of the classical r-selected bacteria [sensitive to the nutrient and growing rapidly] in the mucus layer and the formation of bacterial mat [45]. In such condition, the protective film will be formed by the coral mucus under the bacterial mat to resist the invasion of conditioned pathogens. As a result, the activity and self-regulation of the microbial community attached to the corals were verified. These microbes prevent the adhesion of external bacteria and pathogenic bacteria by competition and niche occupation.

\subsection{Mediating Behavior of Symbiotic Bacteria}

"Coral-bacteria-zooxanthella" is the main body of coral symbiont. The interaction between corals and zooxanthella attracts more attention. The zooxanthellae supply the host with the photosynthetic products such as glucose, glycerin and amino acids as well as $90 \%$ energy; the corals provide protection, habitat, nutrient salts $[\mathrm{N}$ and $\mathrm{P}]$ and the $\mathrm{CO}_{2}$ for photosynthesis [46]. In this mutually beneficial relationship, some ecological behaviors can be independently achieved by the two, but some require the assistance of bacteria. That is to say, the bacteria play the role of mediator in the symbiotic relationship. This mediating function is mainly manifested in three aspects: processing of $\mathrm{N}$ source, regulation of algal quantity and enhancement of coral color.

$\mathrm{N}$ source is required for the growth of corals, but the $\mathrm{N}$ in seawater cannot be absorbed directly by the corals. Therefore, the bacteria are needed to process the N. Moreover, some $\mathrm{N}$-containing macromolecular compounds released by algae can be utilized by corals only after the decomposition by bacteria. As Rosenberg said, in the process of preparing $\mathrm{N}$ source for the coral host, the bacteria play an important role as the mediator, the "nutrition processor" for the host.

In the symbiotic relationship between corals and zooxanthellae, an appropriate proportion of algal quantity should be kept to maintain the ecological balance of the symbiont. Generally, the coral regulates the quantity of zooxanthella by controlling nutrients and light, so as to avoid excess proliferation [47]. However, in the eutrophicated water, the algae can more efficiently utilize the nutrients, and thus proliferate greatly, which brings stress to the corals and affects the coral health. At this moment, the microbes can help the algae to compete for nutrients, thus inhibiting their excess proliferation. Dixson et al [48] investigated the community structure of Acropora nasuta of Fiji, and found that when the environment was disturbed due to the excess proliferation of algae, Acropora nasuta would release some kind of scent to attract symbiotic fishes (goby fish). The goby fish ate these algae, and thus the potential damage on corals was diminished. The release of such scent might require the participation of Proteobacteria in the cavity. It can be seen that Proteobacteria plays the mediating role in the process of regulating algal quantity.

Besides, the bacteria contribute to the color enhancement of the corals. Generally, the color of corals depends on five chromoproteins, including four fluorescent proteins (cyan, green, yellow and red) and one deep violet non-fluorescent protein, which are derived from the coral itself or zooxanthella. When the corals and zooxanthellae are in optimal condition, the bacteria also participate in the color enhancement to make the coral more flamboyant [49]. It was found that Acanthastrea echinata of the Caribbean Sea can absorb the blue light, and present red orange. Literature indicated that the symbiotic bacteria, Cyanobacteria, can transform the $\mathrm{N}$ in seawater into $\mathrm{NH}_{4}{ }^{+}$, providing sufficient $\mathrm{N}$ source for corals. Then the corals can absorb blue light and present red-orange luster [49].

\section{Signaling Strategies of Microbes}

Microbes have evolved sophisticated strategies to gauge their own population densities and accordingly change global patterns of gene regulation. Such population density-dependent cell-to-cell signalling and gene regulation is often termed 'quorum sensing' (QS) [50]. The presence of compounds capable of activating or inhibiting responses of bacterial QS reporters has been documented in the extracts of marine organisms, including corals [51], which suggests that QS-based signalling and signal-interference take place in coral environment. The role of the signaling behavior is mainly related with the disease assistance. Pervious, in situ native coral bacterial isolates capable of inhibiting bacterial QS were also capable of preventing progression of a disease caused by a coral pathogen $S$. marcescens PDL100 in a model polyp Aiptasia pallida [52]. Although the mechanism of how the epiphytic bacteria in the mucus prevent the pathogenic infection is still unclear, some proofs indicate that it may be correlated with quorum sensing (QS) mechanism, the cytochemical signal system. In the coral symbionts, the symbiotic bacteria and the bacteria in the surface mucus can inhibit or activate the production of antibiotics and extracellular enzymes, and the attachment of beneficial bacteria via QS signal. By QS signaling mechanism, the symbiotic microbes have three main ways to resist the pathogens, that is, strengthening their own population, decomposing the QS signal of pathogenic bacteria and generating deceptive QS bait. The study by Alagely et al [53] supported the first way; the epiphytic bacteria won the living space of pathogenic Serratia sp. of corals by self-regulation of QS, hence becoming the dominant species. It was proved by in situ research that the symbiotic bacteria of reef-building corals can generate film, and the degree of maturity of the film is mediated by QS signal. The pathological investigation found that the integrity of film showed negative correlation with the probability of infection of diseases [54]. Teplitski et al [55] indicated that the Proteobacteria sp. of stony corals can withstand the invasion of pathogens by generating acylase or lactonase to decompose the QS molecules in surrounding pathogenic bacteria. Besides signal-degrading enzyme, Skindersoe et al [56] found that the epiphytic bacteria contain the compounds disturbing the QS activity, i.e. they can disturb the colonization of pathogenic bacteria in the 
coral mucus. The third method indicates the smart performance of epiphytic bacteria, that is, they can generate some QS analogue to deceive pathogenic bacteria or interfere with their QS regulation. Rajamani et al [57] revealed that the secondary metabolite of epiphytic bacteria, photopigment (derivative of riboflavin), can interact with the receptor of QS signal and interrupt the downstream process of QS regulation. Moreover, the beneficial bacteria in the symbiotic environment can recognize and sense the QS concentration of pathogenic bacteria, and generate QS analogue to disturb their release of QS signal.

\section{Conclusion}

More and more researches indicate that the microbes play an important role in coral reef due to its multistable regulation and feedback mechanism. Interactions among host-associated bacterial communities are critical for the overall health of the coral holobiont, but our understanding of the mechanisms and consequences of these interactions is still incomplete. In the future, some new techniques should be use, including higher-intelligence model system, in-situ underwater microscope, high-speed drawing capture tool, and microfluidics technique and metagenomic project, which provides convenience for the study and protection of coral reefs.

\section{Acknowledgements}

This work was supported by Guangdong Innovation and Development of Regional Marine Economy Demonstration Projects (SZHY2014-B01-002), the National Natural Science Foundation of Guangdong Province (2014A030313774), Marine Fishery Science and Technology \& Industry Development of Guangdong Province (A201503D07), and S\&T Projects of Shenzhen Science and Technology Innovation Committee (CXZZ20150529165045063).

\section{References}

[1] Wolfgang K, Carl S, Michael F. 2010. Reefs as cradles of evolution and sources of biodiversity in the phanerozoic. Science, 327 [5962): 196-198.

[2] Rohwer F, Seguritan V, Azam F, Knowlton N. 2002. Diversity and distribution of coral-associated bacteria. Marine Ecology Progress Series, 243: 1-10.

[3] Haas AF, Nelson CE, Rohwer F, Wegley-Kelly L, Quistad SD, Carlson CA, Leichter JJ, Hatay M, Smith JE. 2013. Influence of coral and algal exudates on microbially mediated reef metabolism. Peer Journal, 1:e108.

[4] Whittaker RH. 1975. Communities and ecosystems. Macmllan. New York, 129-164.

[5] Rohwer F, Breitbart M, Jara J, Azam F, Knowlton N. 2001. Diversity of bacteria associated with the Caribbean coral Montastraea franksi. Coral Reefs, 20: 85-91.
[6] Sweet MJ, Croquer A, Bythell JC. 2011. Development of bacterial biofilms on artificial corals in comparison to surface-associated microbes of hard corals. PLoS One, 6: e21195.

[7] Augustin R, Fraune S, Bosch TC. 2010. How Hydra senses and destroys microbes. Seminars Immunology, 22: 54-58.

[8] Apprill A, Marlow HQ, Martindale MQ, Rappe MS. 2009. The onset of microbial associations in the coral Pocillopora meandrina. The ISME Journal, 3: 685-699.

[9] Littman RA, Willis BL, Bourne DG. 2009. Bacterial communities of juvenile corals infected with different Symbiodinium [dinoflagellate) clades. Marine Ecology Progress Service, 389: 45-59.

[10] Sharp KH, Distel D, Paul VJ. 2012. Diversity and dynamics of bacterial communities in early life stages of the Caribbean coral Porites astreoides. The ISME Journal, 6: 790-801.

[11] Wegley L, Edwards R, Rodriguez-Brito B, Liu H, Rohwer F. 2007. Metagenomic analysis of the microbial community associated with the coral Porites astreoides. Environmental Microbiology, 9: 2707-2719.

[12] Wagner-Dobler I, Biebl H. 2006. Environmental biology of the marine Roseobacter lineage. Annual Review of Microbiology, 60: 255-280.

[13] Webster NS, Uthicke S, Botté ES, Flores F, Negri AP. 2013. Ocean acidification reduces induction of coral settlement by crustose coralline algae. Global Change Biology, $19[1): 303-315$.

[14] Yi H, Lim YW, Chun J. 2007. Taxonomic evaluation of the genera Ruegeria and Silicibacter: a proposal to transfer the genus Silicibacter Petursdottir and Kristjansson 1999 to the genus Ruegeria Uchino et al. 1999. International Journal of Systematic and Evolutionary Microbiology, 57: 815-819.

[15] Sogin ML, Morrison HG, Huber JA, Mark WD, Huse SM, Neal PR, Arrieta JM, Herndl GJ. 2006. Microbial diversity in the deep sea and the underexplored "rare biosphere". Proceedings of the National Academy of Sciences of the United States of America, 103: 12115-12120.

[16] Fiore CL, Jarett JK, Lesser MP. 2013. Symbiotic prokaryotic communities from different populations of the giant barrel sponge, Xestospongia muta. Microbiologyopen, 2[6):938-952.

[17] Long RA, Azam F. 2001. Microscale patchiness of bacterioplankton assemblage richness in seawater. Aquatic Micrological Ecology, 26: 103-113.

[18] Fuhrman JA, Hewson I, Schwalbach MS, Steele JA, Brown MV, Naeem S. 2006. Annually reoccurring bacterial communities are predictable from ocean conditions. Proc Natl Aca Sci USA 103: 13104-13109.

[19] Hewson I, Jacobson M.M, Fuhrman J. 2007. Diversity and biogeography of bacterial assemblages in surface sediments across the San Pedro Basin, Southern California Borderlands. Environmental Microbiology, 9: 923-933.

[20] Frias-Lopez J, Zerkle AL, Bonheyo GT, Fouke BW. 2002. Partitioning of bacterial communities between seawater and healthy, black band diseased, and dead coral surfaces. Applied and Environmental Microbiology, 68: 2214-2228. 
[21] Klaus JS, Frias-Lopez J, Bonheyo GT, Heikoop JM, Fouke BW. 2005. Bacterial communities inhabiting the healthy tissues of two Caribbean reef corals: interspecific and spatial variation. Coral Reefs, 24: 129-137.

[22] Hong MJ, Yu YT, Chen CA, Chiang PW, Tang SL. 2009. Influence of species specificity and other factors on bacteria associated with the coral Stylophora pistillata in Taiwan. Applied and Environmental Microbiology, 75: 7797-7806.

[23] Jensen S, Lynch MD, Ray JL, Neufeld JD, Hovland M. 2014. Norwegian deep-water coral reefs: cultivation and molecular analysis of planktonic microbial communities. Environ. Microbiol. doi: 10.1111/1462-2920.12531.

[24] Van Oppen MJH, Gates RD. 2006. Conservation genetics and the resilience of reef-building corals. Molecular Ecology, 15: 3863-3883

[25] Williams WM, Viner AB, Broughton WJ. 1987. Nitrogen fixation [acetylene reduction) associated with the living coral Acropora variabilis. Marine Biology, 94: 531-535.

[26] Lesser MP, Mazel CH, Gorbunov MY, Falkowski PG. 2004. Discovery of symbiotic nitrogen-fixing cyanobacteria in corals. Science, 305: 997-1000.

[27] Cardini U, Bednarz VN, Foster RA, Wild C. 2014. Benthic N2 fixation in coral reefs and the potential effects of human-induced environmental change. Ecological Evolution, 4[9):1706-1727.

[28] Lesser MP, Falcon LI, Rodriguez-Roman A, Enriquez S, Hoegh-Guldberg O, Iglesias-Prieto R. 2007. Nitrogen fixation by symbiotic cyanobacteria provides a source of nitrogen for the scleractinian coral Montastraea cavernosa. Marine Ecology Progress Service, 346: 143-152.

[29] Olson ND, Ainsworth TD, Gates RD, Takabayashi M. 2009. Diazotrophic bacteria associated with Hawaiian Montipora corals: diversity and abundance in correlation with symbiotic dinoflagellates. Journal of Experimental Marine Biology and Ecology, 371: 140-146.

[30] Ferrier-Pages C, Schoelzke V, Jaubert J, Muscatine L, Hoegh-Guldberg O. 2001. Response of a scleractinian coral, Stylophora pistillata, to iron and nitrate enrichment. Journal of Experimental Marine Biology and Ecology, 259: 249-261.

[31] Fiore CL, Jarett JK, Olson ND, Lesser MP. 2010. Nitrogen fixation and nitrogen transformations in marine symbioses. Trends Microbiology, 18: 455-463.

[32] Fiore CL, Baker DM, Lesser MP. 2013. Nitrogen biogeochemistry in the Caribbean sponge, Xestospongia muta: a source or sink of dissolved inorganic nitrogen? PLoS One, 8[8):e72961.

[33] Santos HF, Carmo FL, Duarte G, Dini-Andreote F, Castro CB, Rosado AS, van Elsas JD, Peixoto RS. 2014. Climate change affects key nitrogen-fixing bacterial populations on coral reefs The ISME Journal. doi: 10.1038/ismej.2014.70.

[34] Wild C, Huettel M, Klueter A, Kremb SG, Rasheed MYM, Jorgensen BB. 2004. Coral mucus functions as an energy carrier and particle trap in the reef ecosystem. Nature, 428: 66-70.

[35] Nielsen AT, Tolker-Nielsen T, Barken KB, Molin S. 2000 Role of commensal relationships on the spatial structure of a surfaceattached microbial consortium. Environmental Microbiology, 2: 59-68.
[36] Ritson-Williams R, Paul VJ, Arnold SN, Steneck RS. 2010. Larval settlement preferences and post-settlement survival of the threatened Caribbean corals Acropora palmata and $A$. cervicornis. Coral Reefs, 29: 71-81.

[37] Tebben J, Tapiolas DM, Motti CA, Abrego D, Harder T. 2011. Induction of larval metamorphosis of the coral Acropora millepora by tetrabromopyrrole isolated from a Pseudoalteromonas bacterium. PLoS One, 6: e19082.

[38] Tran C, Hadfield MG. 2011. Larvae of Pocillopora damicornis [Anthozoa) settle and metamorphose in response to surface-biofilm bacteria. Marine Ecology Progress Series, 433: 85-96.

[39] Ritchie KB, Smith GW. 2004. Microbial communities of coral surface mucopolysaccharide layers. In: Rosenberg E \& Loya Y, editors. Coral health and disease. Heidelberg [Germany): Springer-Verlag. p. 259-263.

[40] Krediet CJ, Ritchie KB, Paul VJ, Teplitski M. 2013. Coral-associated micro-organisms and their roles in promoting coral health and thwarting diseases. Process Biology Science, 280[1755):20122328.

[41] Ritchie KB. 2006. Regulation of microbial populations by coral surface mucus and mucus-associated bacteria. Marine Ecology Progress Series, 322: 1-14.

[42] Reshef L, Koren O, Loya Y, Zilber-Rosenberg I, Rosenberg E. 2006. The coral probiotic hypothesis. Environmental Microbiology, 8: 2068-2073.

[43] Kelman D, Kashman Y, Rosenberg E, Kushmaro A, Loya Y. 2006. Antimicrobial activity of Red Sea corals. Marine Biology, 149: 357-363.

[44] Geffen Y, Rosenberg E. 2005. Stress-induced rapid release of antibacterials by scleractinian corals. Marine Biology, 146: 931-935.

[45] Allers E, Niesner C, Wild C, Pernthaler J. 2008. Microbes enriched in seawater after addition of coral mucus. Applied and Environmental Microbiology, 74: 3274-3278.

[46] Mieog JC, Olsen JL, Berkelmans RWC, Bleuler-Martinez SA. Willis BL, van Oppen MJH. 2009. The roles and interactions of symbiont, host and environment in defining coral fitness. PLoS ONE, 4[7): e6364.

[47] James PG, Luke DS, Andrew JH, Andrew HB, Morgan SP. 2013. Recovery of an Isolated Coral Reef System Following Severe Disturbance. Science, 340 [6128): 69-71.

[48] Rinkevich B. Novel tradable instruments in the conservation of coral reefs, based on the coral gardening concept for reef restoration. J Environ Manage. 2015, 162:199-205.

[49] Michael L. Bacteria light bulbs inside coral. http://www.eurekalert.org/features/kids/2004-08/aaft-bb02080 5.php.

[50] Krediet CJ, Ritchie KB, Paul VJ, Teplitski M. Coral-associated micro-organisms and their roles in promoting coral health and thwarting diseases. Proc R Soc B. 2013, 280: 20122328.

[51] Skindersoe ME, Ettinger-Epstein P, Rasmussen TB, Bjarnsholt T, de Nys R, Givskov M. Quorum sensing antagonism from marine organisms. Mar. Biotechnol. 2008. 10: 56-63. 
[52] lagely A, Krediet CJ, Ritchie KB, Teplitski M. Signaling-mediated cross-talk modulates swarming and biofilm formation in a coral pathogen Serratia marcescens. ISME J. 2011, 5: 1609-1620.

[53] Alagely A, Krediet CJ, Ritchie KB, Teplitski M. 2011. Signaling-mediated cross-talk modulates swarming and biofilm formation in a coral pathogen Serratia marcescens. The ISME Journal, 5: 1609-1620.

[54] Krediet CJ, Ritchie KB, Cohen M, Lipp EK, Sutherland KP, Teplitski M. 2009. Utilization of mucus from the coral Acropora palmata by the pathogen Serratia marcescens and by environmental and coral commensal bacteria. Applied Environmental Microbiology, 75: 3851-3858.
[55] Teplitski M, Warriner K, Bartz J, Schneider KR. 2011. Untangling metabolic and communication networks: interactions of enterics with phytobacteria and their implications in produce safety. Trends Microbiology, 19: 121-127.

[56] Skindersoe ME, Ettinger-Epstein P, Rasmussen TB, Bjarnsholt T, de Nys R, Givskov M. 2008. Quorum sensing antagonism from marine organisms. Marine Biotechnology, 10: 56-63.

[57] Rajamani S, Bauer WD, Robinson JB, Farrow JM, Pesc EC, Teplitski M, Gao M, Sayre RT, Phillips DA. 2008. The vitamin riboflavin and its derivative lumichrome activate the LasR bacterial quorum-sensing receptor. Molecular Plant Microbes Interaction, 21: 1184-1192. 